\title{
OBSCURE CARDIOPATHY
}

\author{
BY \\ BYRON EVANS \\ From the United Cardiff Hospitals \\ Received August 12, 1956
}

When true cardiac enlargement is found in a patient without evidence of hypertension, coronary arterial disease, valvular defects, congenital lesions, bronchopulmonary disease, or thyrotoxicosis, the ætiology becomes obscure. Such patients often present with arrhythmia or with symptoms and signs of heart failure, and cardiac enlargement is found clinically and by cardioscopy: the heart failure eventually becomes resistant to treatment. After necropsy and microscopical examination of the heart, the actual cause of the illness may still remain obscure. This problem is not uncommon and the object of this paper is to describe four such cases.

The main clinical features are shown in Table I and the necropsy findings in Table II.

TABLE I

Main Clinical Features

\begin{tabular}{|c|c|c|c|c|c|c|c|c|}
\hline Case & Sex & Age & $\begin{array}{l}\text { Family } \\
\text { history }\end{array}$ & Signs & $\begin{array}{l}\text { Blood } \\
\text { pressure }\end{array}$ & $\begin{array}{c}\text { Electrocardiographic } \\
\text { changes }\end{array}$ & Cardioscopy & $\begin{array}{l}\text { Interval between onset } \\
\text { of symptoms and } \\
\text { death, and mode of } \\
\text { death }\end{array}$ \\
\hline 1 & M & 28 & Nil & $\begin{array}{l}\text { Triple rhythm. } \\
\text { Transient S.M. } \\
\text { at apex }\end{array}$ & $120 / 80$ & $\begin{array}{l}\text { A.F. Wide QRS. } \\
\text { Deep Q in 1, V4, } \\
\text { V6. Inverted T in } \\
\text { V6 }\end{array}$ & $\begin{array}{l}\text { R.V. }++ \\
\text { L.V. }++\end{array}$ & $\begin{array}{l}2 \text { yr. Heart failure. } \\
\text { (Previous pulmonary } \\
\text { infarcts) }\end{array}$ \\
\hline 2 & $\mathbf{M}$ & 47 & Nil & No murmurs & $120 / 70$ & E. S. Partial L.B.B.B1. & $\begin{array}{l}\text { R.V. }++ \\
\text { L.V. }++\end{array}$ & 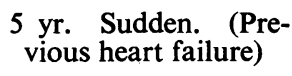 \\
\hline 3 & $\mathbf{M}$ & 51 & Nil & S.M. at apex & $130 / 80$ & $\begin{array}{l}\text { P-R interval long. } \\
\text { R.B.B.Bl. Later } \\
\text { A.F. }\end{array}$ & $\begin{array}{l}\text { RV. }++ \\
\text { L.V. }++\end{array}$ & $\begin{array}{l}3 \text { yr. Heart failure. } \\
\text { (Previous splenic and } \\
\text { renal infarcts) }\end{array}$ \\
\hline 4 & $\mathrm{~F}$ & 41 & Nil & $\begin{array}{l}\text { Triple rhythm. } \\
\text { S.M. at apex }\end{array}$ & $120 / 80$ & A.F. Inverted $T$ in & $\begin{array}{l}\text { R.V. }+ \\
\text { L.V. }+\end{array}$ & $\begin{array}{l}2 \text { yr. Heart failure. } \\
\text { (Previous splenic and } \\
\text { renal infarcts) }\end{array}$ \\
\hline
\end{tabular}

\section{CASE REPORTS}

Case 1. A man, aged 28, had served in the Merchant Navy visiting many countries, including East and West Africa. His parents and four sisters and one brother had healthy hearts. Five months previous to his admission to hospital mass miniature radiography had shown moderate cardiac enlargement. His main symptoms were cough, breathlessness, hæmoptysis, and swelling of the legs. There were gross signs of heart failure. Auricular fibrillation was present and the heart was much enlarged and this was confirmed radiologically (Fig. 1A). The heart sounds were normal, no murmurs were heard, and the blood pressure was $120 / 80 \mathrm{~mm}$. Hg. Pericardial effusion was suspected at one stage, but fluid was not obtained by aspiration. The cardiogram (Fig. 2) showed auricular fibrillation, low voltage, wide QRS complexes, deep Q 
TABLE II

SUMMARY OF NECROPSY FINDINGS

\begin{tabular}{|c|c|c|c|c|c|c|}
\hline Case & $\begin{array}{l}\text { Weight } \\
\text { (grams) }\end{array}$ & $\begin{array}{l}\text { Thickness } \\
\text { of R.V. } \\
\text { (mm.) }\end{array}$ & $\begin{array}{l}\text { Thickness } \\
\text { of L.V. } \\
\text { (mm.) }\end{array}$ & $\begin{array}{c}\text { Ante-mortem } \\
\text { thrombus }\end{array}$ & Coronary arteries & Histological changes \\
\hline 1 & 740 & 10 & 20 & Present & $\begin{array}{l}\text { Small right and circumflex } \\
\text { of left. All patent }\end{array}$ & $\begin{array}{l}\text { Interstitial and endocardial } \\
\text { fibrosis. Hypertrophy of } \\
\text { muscle fibres }\end{array}$ \\
\hline 2 & 620 & 6 & 19 & Absent & Small right. All patent & $\begin{array}{l}\text { Slight sub-endocardial and } \\
\text { focal myocardial fibrosis. } \\
\text { Marked hypertrophy of } \\
\text { muscle fibres }\end{array}$ \\
\hline 3 & 560 & 7 & 10 & Present & $\begin{array}{l}\text { Normal size and patent } \\
\text { except for lumen of left } \\
\text { descending branch which } \\
\text { was one-third occluded }\end{array}$ & Diffuse myocardial fibrosis \\
\hline 4 & 405 & 5 & 14 & Present & $\begin{array}{l}\text { Normal size and patent. } \\
\text { Localized eccentric intimal } \\
\text { thickening of left }\end{array}$ & $\begin{array}{l}\text { Focal and diffuse myocar- } \\
\text { ditis. Endocardial and } \\
\text { myocardial fibrosis }\end{array}$ \\
\hline
\end{tabular}

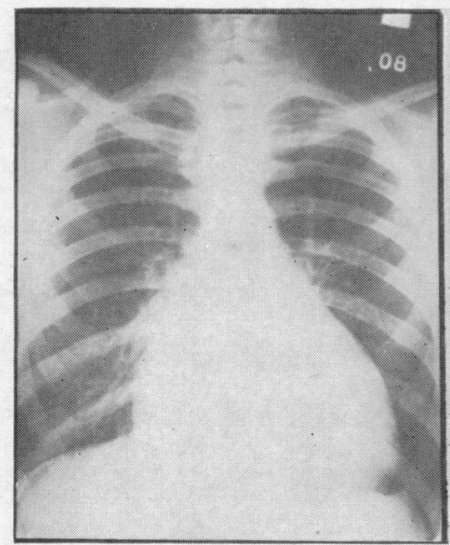

A

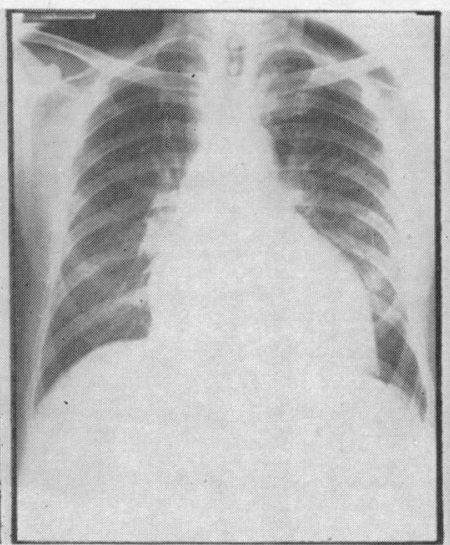

B

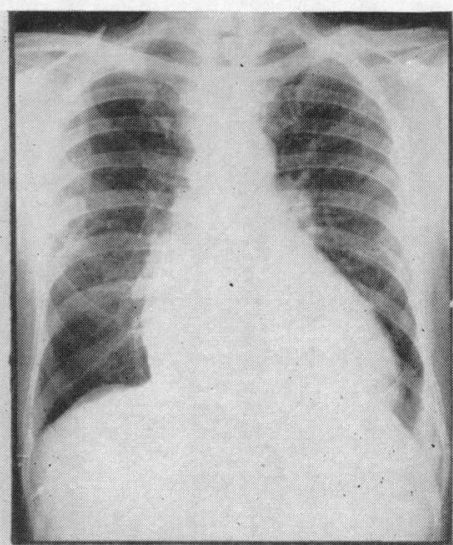

C

Fig. 1.-(A) Symmetrical enlargement of the heart. Case 1. (B) Great enlargement of the heart with early pulmonary congestion. Case 2. (C) Cardiac enlargement predominantly to the left with a small left-sided effusion. Case 3.
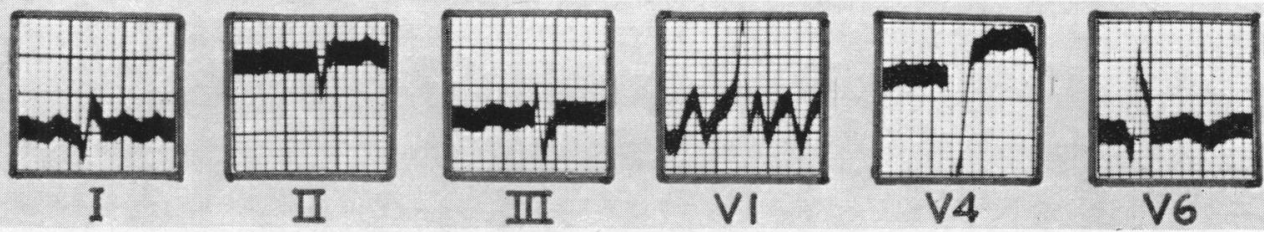

FIG .2.-Auricular fibrillation; wide QRS complexes; deep Q waves in 1, V4, and V6; and inverted T waves in V6. Case 1 . 
waves in leads 1, V4, and V6, and inverted T waves in V6. The blood count, plasma proteins, and blood urea were within normal limits, and the Wassermann and Kahn reactions were negative. He remained in hospital for six months and eventually the signs of heart failure disappeared, but he was subsequently readmitted three times because of heart failure. He developed a triple rhythm and a transient musical systolic murmur was occasionally heard in the mitral area. He died after repeated pulmonary infarctions and the terminal development of gangrene of his toes and heels.

At necropsy by Dr. T. E. Parry, the pericardium was found to be normal and the cavity contained about $110 \mathrm{ml}$. of clear straw-coloured fluid. The heart was grossly enlarged and weighed $740 \mathrm{~g}$. The right atrium was dilated and its walls thickened. Both ventricles were dilated and hypertrophied (R.V. $10 \mathrm{~mm}$., L.V. $20 \mathrm{~mm}$. thick). The valves were normal. Several adherent antemortem mural thrombi were present in both atria. One of these protruded from the left atrium through the dilated mitral valve producing a ball-valve obstruction of the orifice (Fig. 3). The endocardium of the atria was slightly thickened and that of the ventricles was thin and translucent. White streaks and patches of fibrosis were evident

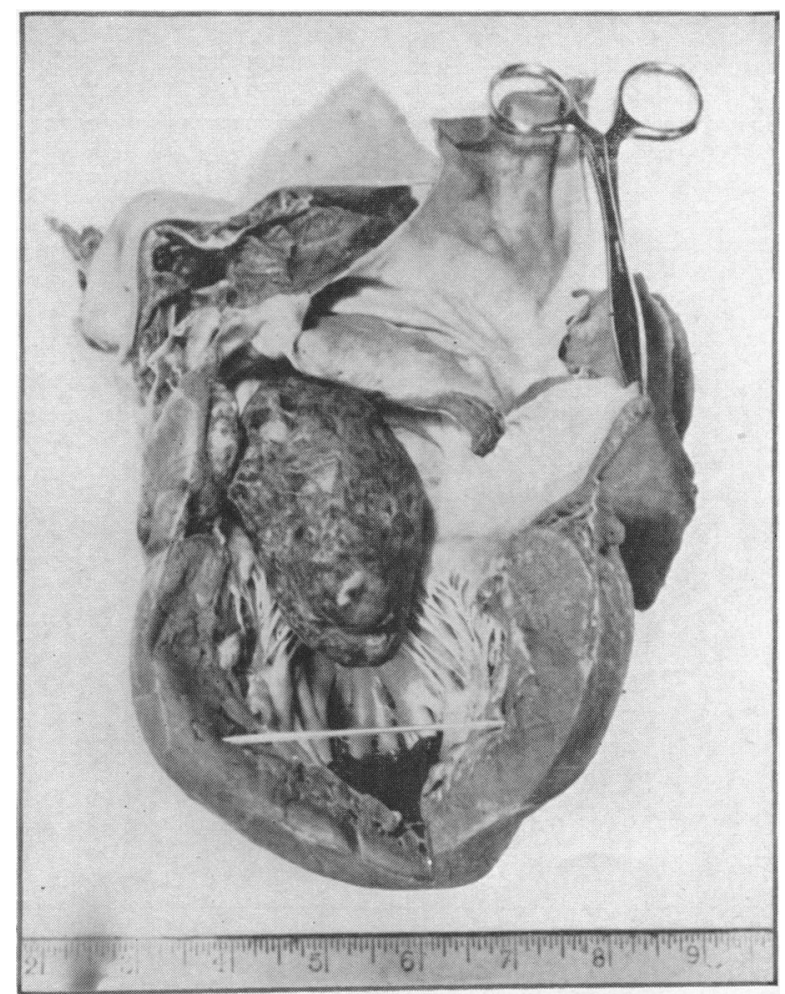

FIG. 3.-Hypertrophy of left ventricle; a large mural thrombus protruding through the mitral valve. Case 1.

on the cut surface of the wall of the left ventricle. The aorta was smaller than normal. The two coronary arteries arose normally from the aorta and were free of atheroma. The right coronary artery, and in particular, the circumflex branch of the left coronary artery were small having regard to the size of the ventricles. The left pleura contained a hæmorrhagic effusion and several infarcts were present in the lungs. Microscopical examination of the atria showed hypertrophy of the muscle fibres and a moderate degree of interstitial and endocardial fibrosis, and the ventricular walls showed a pronounced degree of interstitial fibrosis with hypertrophy of the muscle fibres (Fig. 4). Aschoff nodes were not seen.

Case 2. A man, aged 47, had served in the Army from 1941 to 1946 and had been in Burma and West Africa. His father was alive and well and had extrasystoles. His mother died of rheumatic valvular disease which was proved at necropsy. Five years before he died he began to have paroxysms of tachycardia and his heart then was of normal size. These attacks recurred at intervals, and for two 
months before he was seen the tachycardia had persisted. During this time he had become breathless with swelling of his legs. On admission to hospital he was cyanosed and orthopnœic, the pulse was rapid and irregular from extrasystoles, and the apex beat was displaced to the anterior axillary line. The sounds were normal, no murmurs were present, and the blood pressure was $120 / 70 \mathrm{~mm}$. Signs of heart failure were present. On cardioscopy (Fig. 1B) there was great enlargement of the heart with pulmonary congestion. Serial radiographs during the next five months showed no appreciable change in the appearances. The electrocardiogram (Fig. 5) showed extrasystoles, wide QRS complexes, and partial left bundlebranch block. Further cardiograms were taken at weekly intervals and these showed wider QRS complexes

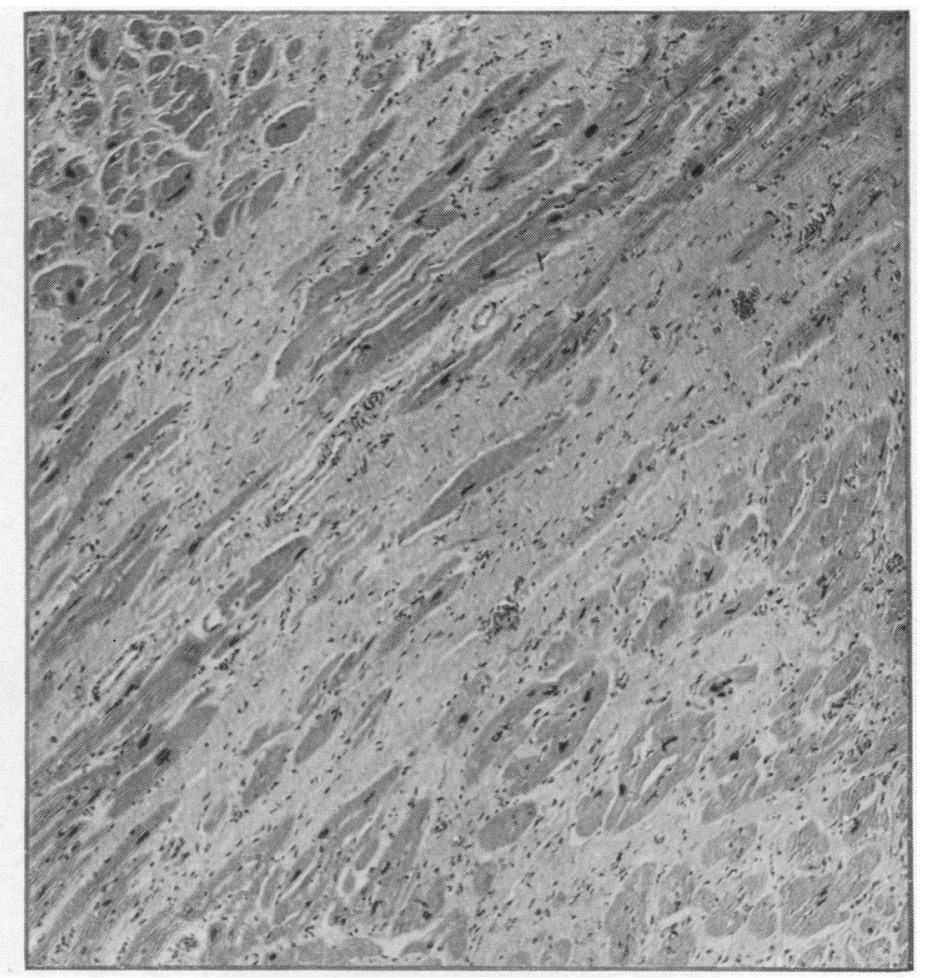

FIG. 4.-Interstitial fibrosis and hypertrophy of muscle fibres of myocardium of right ventricle. $\times 58$. Case 1 .

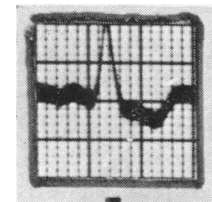

I

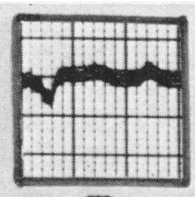

II

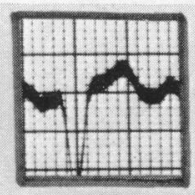

III

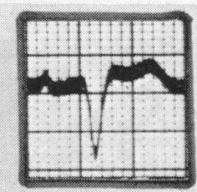

VI

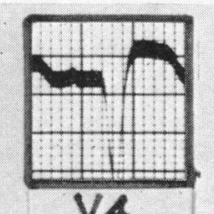

V4

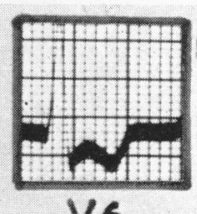

V6

FIG. 5.-Extrasystoles; wide QRS complexes; and partial left bundle-branch block. Case 2.

and coupling. The blood count and plasma proteins were normal, and the Wassermann and Kahn reactions were negative. He responded to treatment and the signs of failure disappeared. Digitalis therapy was continued on leaving hospital and he resumed his occupation as a clerk. Two years later he died suddenly in the street.

At necropsy by Dr. W. R. L. James, the pericardium was found to be normal. The heart was enlarged and weighed $620 \mathrm{~g}$. The enlargement affected both sides of the heart equally. The wall of the right 
ventricle measured $6 \mathrm{~mm}$. and that of the left $19 \mathrm{~mm}$. in thickness. The right coronary artery had a small ostium and was small throughout its length without atheroma, the left showed a slight degree of atheroma near its origin, and both were patent. The heart muscle was thick but otherwise normal to the naked eye. There was no defect of the valves, endocardium, or of the septa of the heart. The aorta was normal. Microscopical examination showed that the heart muscle fibres were enlarged and there was slight vacuolation of the cytoplasm in the region of the nuclei, and slight fibrosis of the subendocardial zone of the myocardium. Throughout the heart muscle there were scanty foci of fibrosis, the largest being less than $2 \mathrm{~mm}$. across. There was a very slight increase of the perivascular connective tissue (Fig. 6). Special staining of the myocardium did not show any accumulation of lipoid material.

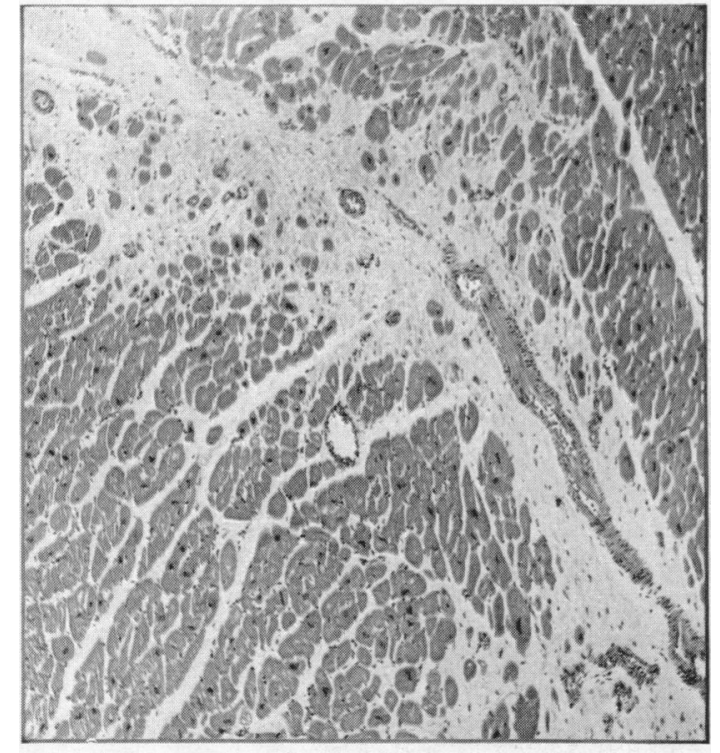

FIG. 6.-Slight increase in fibrous tissue and hypertrophy of muscle fibres of myocardium of left ventricle. $\times 46$. Case 2 .

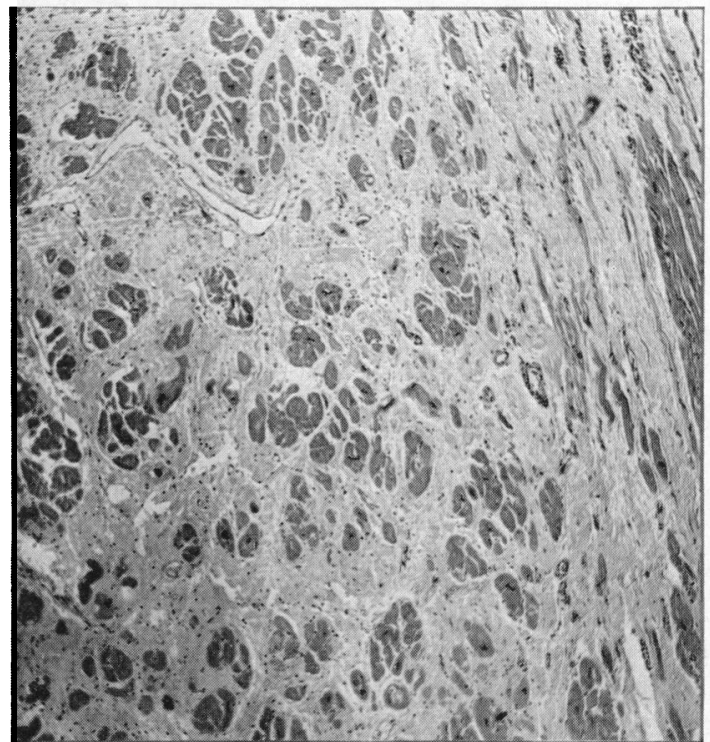

FIG. 7.-Myocardium of left ventricle, showing diffuse fibrosis. $\times 46$. Case 3 .

Case 3. A man, aged 51, was employed as a clerk and had never been abroad. His father had died at the age of 28 and the cause of death was unknown. His mother, aged 78, was alive and well. Two years previously he had been breathless. A systolic murmur heard in the mitral area was thought to be due to mitral valve disease and on cardioscopy there was enlargement of the left ventricle, but no good evidence of left atrial enlargement. On the day previous to his admission to hospital he had experienced difficulty in speaking, but within two minutes he recovered. He also had some weakness of his right limbs, but was able to walk to the hospital where he showed signs of a right hemiparesis. The pulse rate was 68 and irregular from extrasystoles. The apex beat was displaced to the anterior axillary line. There was a harsh systolic murmur in the mitral area. The blood pressure was $130 / 80 \mathrm{~mm}$. and there were no signs of heart failure. The weakness of the right limbs slowly improved, but three weeks after admission he showed signs of heart failure that persisted in spite of treatment. The blood count, serum proteins, and serum electrolytes were normal. On cardioscopy (Fig. 1C) there was cardiac enlargement mainly of the left ventricle, but slightly of the right ventricle. The cardiogram (Fig. 8) showed low voltage, prolonged P-R interval, wide QRS complexes, and right bundle-branch block. Later he developed auricular fibrillation. He died with signs of cardiac failure three years from the start of his illness.

At necropsy by Dr. R. A. Parker, the pericardium was found to contain $20 \mathrm{ml}$. of clear straw-coloured fluid. There was slight fibrinous pericarditis over one area $3 \mathrm{~cm}$. across. The heart was enlarged and weighed $560 \mathrm{~g}$. The left ventricle was dilated and its wall measured $10 \mathrm{~mm}$. in thickness; the right was hypertrophied and its wall measured $7 \mathrm{~mm}$. in thickness. There was a mural thrombus $3 \mathrm{~cm}$. across at the apex of the left ventricle. The valves and septa were normal. The coronary arteries were normal and without atheroma with the exception of $1 \mathrm{~cm}$. in the left descending branch where the lumen was one-third 


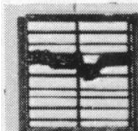

I

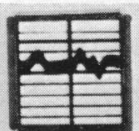

II

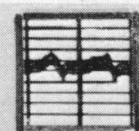

III

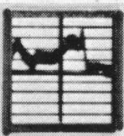

VI

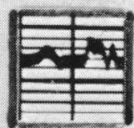

V4

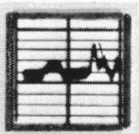

V6

FIG. 8.-Prolonged P-R interval; wide QRS complexes; and right bundle-branch block. Case 3.

occluded. There was an old area of softening $1 \mathrm{~cm}$. across in the internal capsule of the brain. Chronic venous congestion of the liver, left pleural effusion, and infarcts in the spleen and the right kidney were also found. Microscopical examination showed diffuse fibrosis of the myocardium (Fig. 7). The myocardium under the thrombus showed the same changes.

Case 4. A Jamaican woman, aged 41. Her father died at the age of 57 as a result of an accident and her mother at the age of $\mathbf{8 0}$ from an unknown cause. There was no family history of heart disease and each of her six children had a normal-sized heart. Five years before her admission to hospital she had developed a cough and a radiograph at that time showed slight cardiac enlargement. Five weeks before she was seen she became breathless on exertion and this became progressively worse, and was followed by swelling of the legs. There were gross signs of heart failure. The pulse rate was 130 and the rhythm regular. The apex beat was displaced one inch beyond the mid-clavicular line. There was a triple rhythm present and a soft systolic murmur in the mitral area. The blood pressure was $120 / 80 \mathrm{~mm}$. On cardioscopy there was generalized cardiac enlargement affecting both ventricles. The cardiogram showed sinus tachycardia and inverted T wave in V4. She responded well to treatment and was discharged two months later. Within four months she developed auricular fibrillation which was controlled by digitalis therapy. She continued to be breathless on slight exertion and fifteen months later was readmitted in gross cardiac failure which again responded to treatment. During this admission she showed signs of renal and splenic infarction. On cardioscopy, the heart was larger and the electrocardiogram (Fig. 9) confirmed the auricular fibrillation
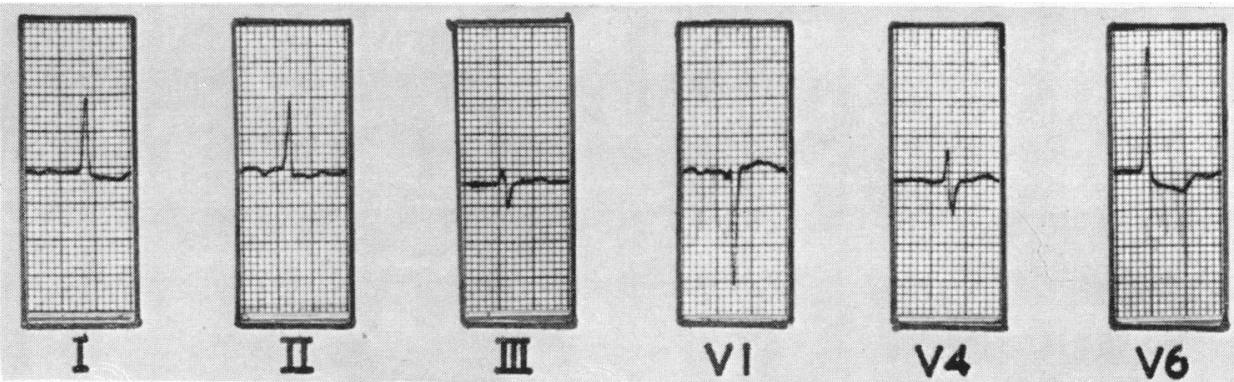

FIG. 9.-Auricular fibrillation; and inverted $\mathrm{T}$ waves in V6. Case 4.

and showed inverted T waves in V6. The blood count was normal. Dr. I. A. B. Cathie tested the patient's serum for toxoplasmosis and found that the dye test was positive at 1/16 and that the complement fixation test was negative. The Wassermann and Kahn reactions were negative. She was discharged from hospital but one month later was readmitted in a moribund condition with signs of pulmonary œedema and died the same day.

At necropsy by Dr. F. K. Storring, the pericardium was found to contain $160 \mathrm{ml}$. of straw-coloured clear fluid. The heart weighed $405 \mathrm{~g}$. There was dilatation and hypertrophy of the left ventricle, $14 \mathrm{~mm}$. thick, dilatation of the right ventricle, $5 \mathrm{~mm}$. thick, right atrium, and right auricle. All the valves were normal and the chordæ tendineæ were thin. The endocardial lining of the chambers of the right side of the heart appeared normal, but that lining the left side of the heart was thickened. The endocardial thickening was greater in the left atrium and auricular appendage than in the left ventricle. The coronary arteries were patent throughout; their walls were thin except for the left coronary artery which showed an eccentric thickening of its intima just distal to the point of origin of the anterior descending branch. The muscle did not show any macroscopic abnormality. Congested and œdematous lungs, chronic venous congestion of the liver, and infarcted areas in the spleen and kidneys were also found. Microscopical 
examination of the heart showed interstitial perivascular and patchy focal fibrosis (Fig. 10) with diffuse infiltration of the interstitial connective tissue with chronic inflammatory cells composed mainly of lymphocytes, plasma cells, mononuclear cells with somewhat large basophilic cytoplasm, and degenerative cells with pyknotic nuclei. In addition, focal collections of similar chronic inflammatory cells were occasionally seen in the areas of perivascular fibrosis in relation to the vessels (Fig. 11) as well as in the patchy areas of fibrosis with evidence of muscle destruction in the latter. The endocardium of the left ventricle, including the interventricular septum, the left atrium, and left auricle was thickened. In the section taken from the left auricle a small organized mural thrombus was present. The left coronary artery showed at one point an eccentric atheromatous thickening but it was patent.

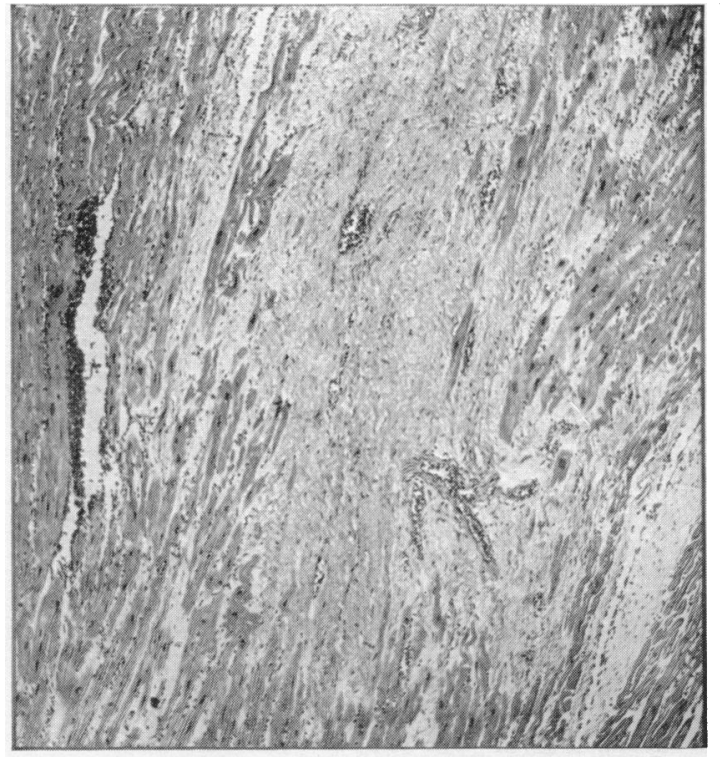

FIG. 10.-Myocardium of left ventricle, showing area of fibrosis. $\times 46$. Case 4 .

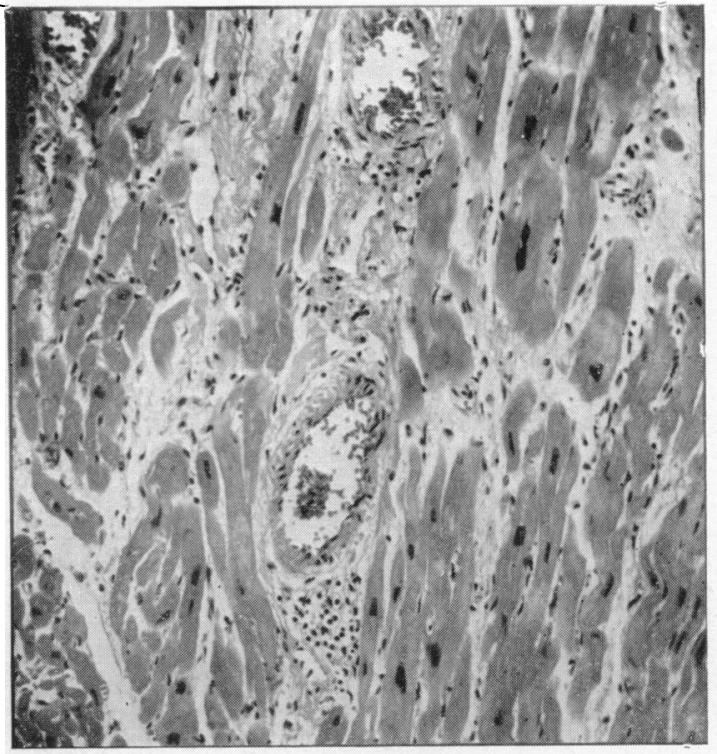

Fig. 11.-Myocardium of left ventricle, showing perivascular and interstitial fibrosis with lymphocytes and plasma cells in relation to coronary vessels. $\times 110$. Case 4 .

\section{DiAGNOSIS}

The conditions that suggested themselves before a diagnosis of myocardial fibrosis was made in these cases were pericardial effusion, constrictive pericarditis, coronary artery disease, mitral valve disease, and thyrotoxicosis. The radiological interpretation in the first case favoured a pericardial effusion and the diagnosis was so much in doubt at first that an exploring needle was introduced, but no fluid was obtained. The presence of a very large heart and the absence of greatly distended cervical veins and liver and of a sound in early diastole appeared to rule out the diagnosis of constrictive pericarditis. In the second case the paroxysms of tachycardia and the cardiographic tracings at one stage suggested coronary arterial disease, but later curves failed to substantiate this diagnosis. Mitral valve disease was thought to be present in the third case at first because of the loud systolic murmur in the mitral area, but cardioscopy failed to show an enlarged left atrium. When the fourth patient developed auricular fibrillation it was thought that thyrotoxicosis might have been missed, but she derived no benefit from antithyroid therapy. No attempt has been made to include all the diseases that enter into the differential diagnosis of cases that present with cardiomegaly, and mention has only been made of the conditions that were considered in these particular cases. 


\section{Discussion}

Bedford and Konstam (1946) recorded a series of 40 cases with endomyocardial fibrosis occurring in African soldiers, all of whom had cardiomegaly and signs of heart failure: necropsy in 17 showed normal coronary arteries but some subendocardial necrosis and fibrosis, endocardial fibrosis, and hypoplasia of the aorta. They did not know the cause of this syndrome, but considered whether nutrition or a constitutional factor associated with the aortic hypoplasia might be operative. Similar lesions were found in 20 Africans reported by Ball et al. (1954): of these, 10 had mitral incompetence, 2 had tricuspid incompetence, and 2 had both these lesions; 4 had healthy valves and 2 had extensive endocardial fibrosis of the right ventricle with distortion of the cavity to such a degree as to almost obliterate the tricuspid orifice. The lesions were essentially fibrosis of the endocardium and underlying myocardium at or near the apex of the ventricles with thrombus formation on the abnormal endocardium, the fibrous tissue spreading upwards and involving the papillary muscles, chordæ, and cusps. Histologically, cellular fibrous tissue was found in the thickened endocardium and strands of this tissue penetrated into the myocardium. No cause was found for the condition but virus infection, some antigen-antibody reaction, and malnutrition were considered possible ætiological factors. In the cases reported here the essential fibrotic lesions were found in the myocardium and are therefore unlike those described by Konstam and Bedford and by Ball et al. The endocardium was only slightly involved in the disease process in the first two cases and in Case 4 the thickened endocardium was more prominent in the left atrium than in the left ventricle, and in this case the main lesions were those of chronic diffuse interstitial myocarditis. No signs of progressive liver disease were found in these cases and they were therefore dissimilar from the 30 Bantu patients described by Gillanders (1951). Becker et al. (1953) described 40 cases that died from heart failure: at necropsy the heart showed dilatation without hypertrophy, subendocardial necrosis or fibrosis, fibrosis of the papillary muscles, and focal or diffuse thickening of the endocardium. The microscopical picture was that of degeneration of collagen and its associated ground and cement substances. Widespread focal involvement of the connective tissue throughout the body was demonstrated. Most of their cases had a prolonged pyrexia and the average duration of life was six months. The clinical picture and the necropsy findings are quite unlike the four cases described here. Paulley et al. (1956) has recently recorded four cases of myocardial toxoplasmosis presenting as cardiomegaly with positive serological tests: the tests were only performed in Case 4 and they were negative.

The four cases recorded here had cardiac hypertrophy with no signs to indicate the more common causes of heart disease. All had abnormal electrocardiograms and even in the reported cases of myocardial fibrosis right bundle-branch block (as shown in Case 3) is rare. Three had embolic phenomena and all showed signs of heart failure. The microscopical findings, although similar, were not identical in all the cases-interstitial fibrosis, slight endocardial fibrosis, and hypertrophy of the muscle fibres in the first; very slight subendocardial and focal fibrosis with much muscle fibre hypertrophy in the second; diffuse fibrosis of the myocardium in the third; and active diffuse interstitial myocarditis with myocardial and endocardial fibrosis in the fourth case. They all showed, however, a fibrotic reaction in the myocardium.

The clinical and pathological features of the first three patients are similar to those described by Evans (1949) and thus are probable examples of familial cardiomegaly, but in none of the three was there any positive family history: such cases, however, can occur sporadically and de novo as in the four isolated cases in Evans' series. In addition to the myocardial and endocardial fibrosis in Case 4 there was evidence of a more active process as was shown by the cellular infiltration. The ætiology in all these cases remains obscure, even if it be similar in all. It is doubtful whether the small right coronary artery noted in Cases 1 and 2 is of any significance, but it is of interest that Campbell and Turner-Warwick (1956) in a description of familial cases, similar otherwise to the present series, noted that the coronary arteries were small as compared with the greatly hypertrophied left ventricle in their two patients that came to necropsy. It is possible that a virus, as 
yet unidentified, will eventually be found to be the infective agent responsible for these obscure cases of cardiopathy.

\section{SUMMARY}

The clinical features of four cases that presented with cardiac hypertrophy and heart failure, but without the signs of the more common forms of heart disease, are described. In each the basic pathological lesion was a myocarditis with a fibrotic reaction in the myocardium.

My thanks are due to Dr. William Evans for his advice, and also to Professor H. Scarborough for his permission to publish Case 3.

\section{REFERENCES}

Ball, J. D., Williams, A. W., and Davies, J. N. P. (1954). Lancet, 1, 1049.

Becker, B. J. P., Chatgidakis, C. B., and van Lingen, B. (1953). Circulation, 7, 345.

Bedford, D. E., and Konstam, G. L. S. (1946). Brit. Heart J., 8, 236.

Campbell, M., and Turner-Warwick, M. (1956). Brit. Heart J., $18,393$.

Evans, W. (1949). Brit. Heart J., 11, 68.

Gillanders, A. D. (1951). Brit. Heart J., 13, 177.

Paulley, J. W., Jones, R., Green, W. P. D., and Kane, E. P. (1956). Brit. Heart J., 18, 55. 